\title{
Introduction of Cloud Break Procedures for Czech Republic based on GNSS SBAS
}

\author{
Jakub Kraus \\ Department of Air Transport, \\ Department of Air Transport, Faculty of Transportation Sciences, Czech Technical University \\ Horská 3, Praha 2, 128 03, Czech Republic \\ e-mail:krausjak@fd.cvut.cz
}

\begin{abstract}
This article focuses on improvements in General Aviation in Czech Republic by introduction of Cloud Break Procedures.
\end{abstract}

Keywords - cloud break procedure, IFR, VFR, GNSS, SBAS, CBP

\section{INTRODUCTION}

General Aviation (GA) is a rapidly growing aviation sector and despite the problems and stagnation in commercial air traffic, has great hope for constant growth. Unfortunately, the GA is overlooked by aviation authorities for decades. Therefore it is necessary to give an impulse, which would shift GA further. This impulse is EGNOS.

The use of EGNOS (European SBAS) is progressing by giant steps forward. So far however, procedures using this technology are introduced mainly for approach and landing, and only in a few European countries, while navigation using GPS with SBAS can achieve sufficient accuracy for procedures, which could not be considered if they were based on conventional navigation means.

\section{CLOUD BREAK PROCEDURES}

Procedures called Cloud Break Procedures (CBP) are used throughout the world. Unfortunately, this name always stands for something else. In this article, however, this phrase is used according to its exact meaning. Thus, the procedure for certain descends through cloud layers, which prevents the visibility of the ground. These procedures are most often used in countries with mountainous terrain where when flying VFR could be found clouds shrouding the destination aerodrome, for example, in the valley.

From the perspective of the Czech Republic, it would seem that such procedures are not necessary, but the opposite is true. When flying VFR the weather can suddenly deteriorate and clouds begin to form below the airplane. In this case, the pilot should land immediately. However, if the clouds grow faster than the aircraft comes to the aerodrome and land safely, critical situation is formed. Aircraft flying VFR ceases to have a visual reference of the ground and has no way to navigate. For such cases should be created a cloud break procedures, which allow safe descent through clouds to regain visual reference information.
Currently in Europe, Cloud Break Procedures are used in Iceland or in Switzerland.

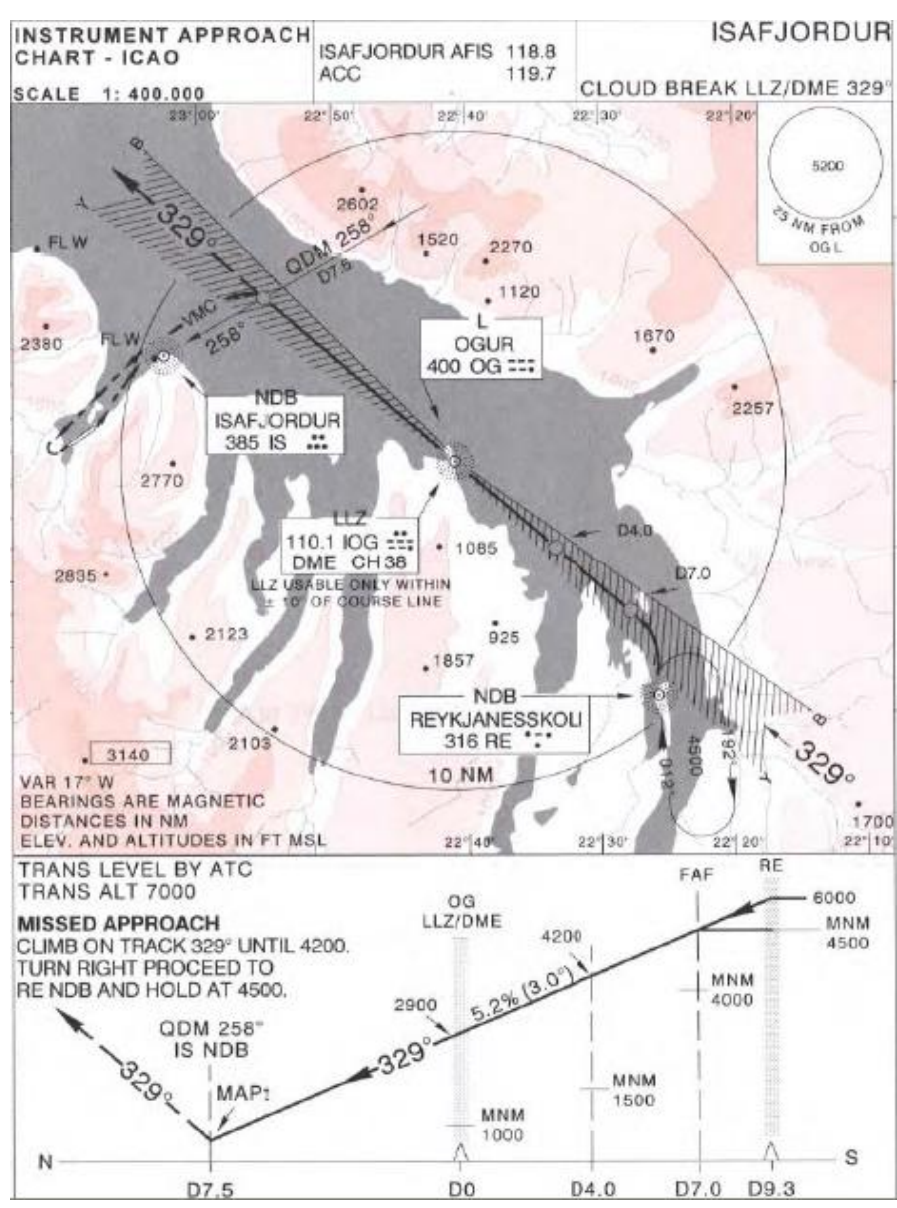

Figure 1. Instrument Approach Chart showing CBP in Iceland for BIIS

In Iceland, CBP are used for approach through the clouds. Consequently, it is necessary to complete the approach and landing in VMC. Navigation device for this approach is NDB or LLZ. An important difference against instrument approach is that the final phase of CBP don't direct airplane to extended runway centerline.

In the Czech Republic these procedures could be introduced at larger GA aerodromes with heavy traffic. 
TABLE I. GA AERODROMES WITH PAVED RWY AND SUFFICIENT LENGTH $(>600 \mathrm{M})$

\begin{tabular}{|l|l|}
\hline Aerodrome & ICAO code \\
\hline České Budějovice & LKCS \\
\hline Hořovice & LKHV \\
\hline Hosín & LKHS \\
\hline Hradec Králové & LKHK \\
\hline Jindřichův Hradec & LKJH \\
\hline Mnichovo Hradiště & LKMH \\
\hline Otrokovice & LKOT \\
\hline Panenský Týnec & LKPC \\
\hline Plzeň - Líně & LKLN \\
\hline Přerov & LKPO \\
\hline Př́bram & LKPM \\
\hline Vysoké Mýto & LKVM \\
\hline
\end{tabular}

TABLE II. GA AERODROMES WITH GRASS RUNWAY AND SUFFICIENT LENGTH

\begin{tabular}{|l|l|}
\hline Aerodrome & ICAO code \\
\hline Benešov & LKBE \\
\hline Cheb & LKCB \\
\hline Chomutov & LKCH \\
\hline Kladno & LKKL \\
\hline Klatovy & LKKT \\
\hline Letňany & LKLT \\
\hline Liberec & LKLB \\
\hline Most & LKMO \\
\hline Plasy & LKPS \\
\hline
\end{tabular}

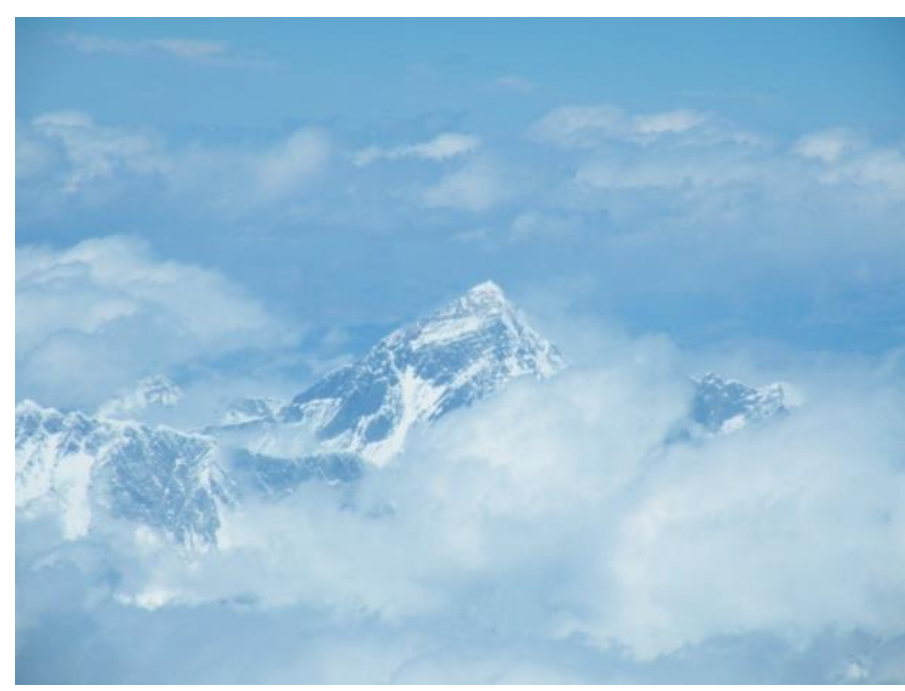

Figure 2. Illustration of conditions for CBP (you can see the ground, but cannot see the aerodrome)

\section{InTROdUCtion OF CLOUd BREAK PROCEDURES IN CZECH REPUBLIC}

$\mathrm{CBP}$ can be used in three ways:

a) IFR flight with final segment in VMC

b) VFR flight with transition to IFR for the use of CBP with final segment in VMC

c) Part of the VFR flight

Of the above options is clear that first is necessary to define whether CBP will be under IFR rules, or not, and whether the procedure will be part of an approach to land, or only procedure to regain visual contact with the ground. The greatest benefit would be the possibility c).

In situations of sudden weather deterioration is problem with general aviation aircraft flying VFR with the visibility of the ground and therefore the safety of flight and landing. The rules of the air define that VFR flight shall not be performed if there is a possibility that weather conditions deteriorate during the flight so much to affect the flight safety. This rule must be met, however, there is only one way to do it and it is by cancelling the flight.

For extra safety it would be appropriate to allow a flying VFR aircraft to fly certain flight segment without VMC.

In the Czech Republic CBP would be based on GNSS navigation. This option is the easiest choice and avionics capable of providing accurate information about the position is available and compatible to most general aviation aircraft.

There are two ways to define the CBP. Using a Restricted Area or without it.

\section{A. Cloud Break Procedures with Restricted Area}

Restricted Area (RA) should be located near the aerodrome, for which it is intended to ensure the operation in deteriorating weather and at a sufficient distance to not restrict normal VFR flights. RA would be activated only in time of weather conditions deterioration. In this restricted area would be certain waypoint - the start of CBP.

The information about the height of cloud base is necessary for the pilot before using CBP. The ceiling must be higher than $1200 \mathrm{ft}$ AGL. If it is below this height, CBP cannot be used. After obtaining information about the cloud base pilot applies for a clearance to enter the restricted area, which will be issued by air traffic controller. Pilot then must intercept defined waypoint with GNSS navigation and after its flyover begin to descend at a constant rate and speed. After the plane gets through clouds leaves Restricted Area and report this to ATC.

The second option is to define the CBP with "missed descent", which would be equivalent to the missed approach procedure, here defined with MDH $1200 \mathrm{ft}$. 

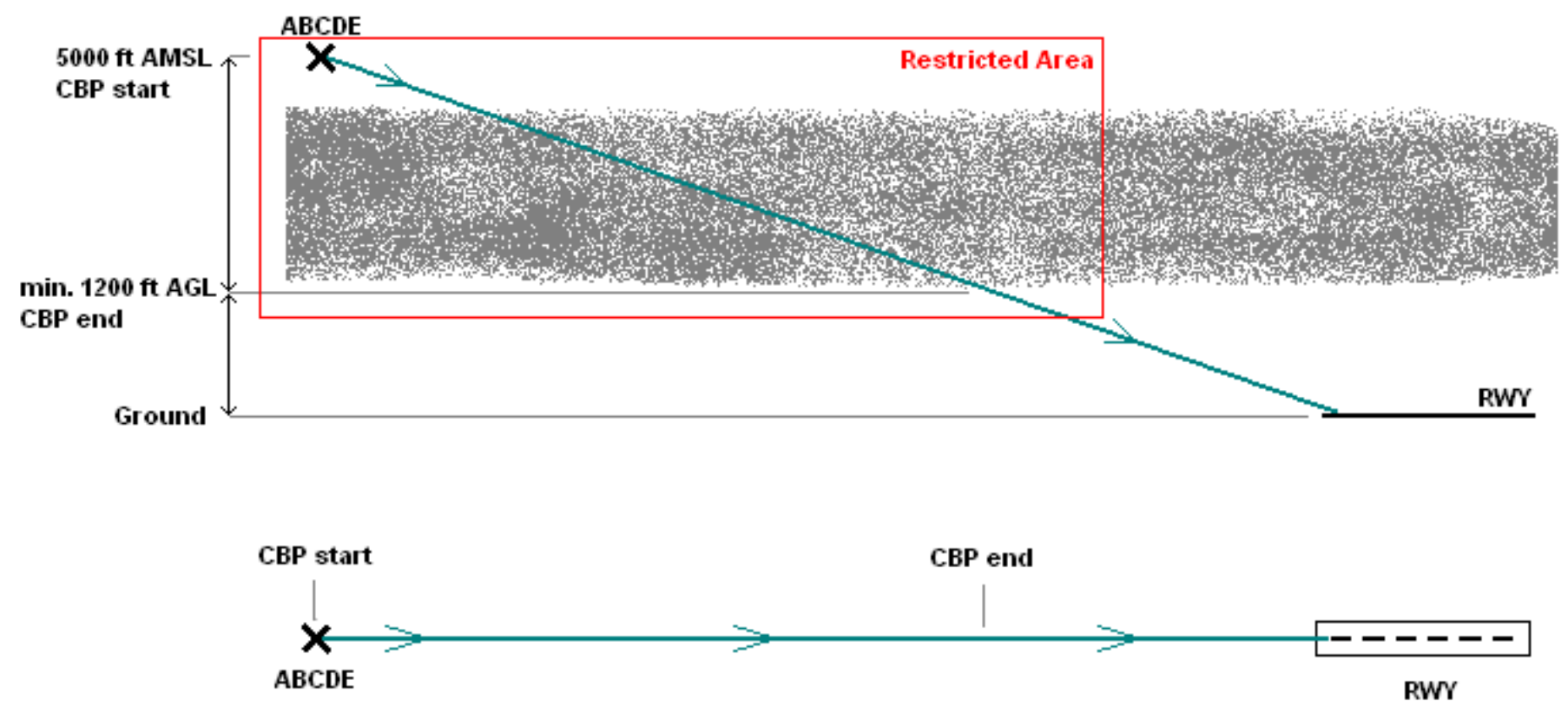

Figure 3. CBP with the use of Restricted Area

For safety reasons, only one plane can be flying in a restricted $\mathrm{CBP}$ area at the same time. This ensures ATC with issuing clearances to start cloud break procedure.

\section{B. Cloud Break Procedures without Restricted Area}

If CBP were implemented without restricted area, it is necessary to provide spacing between aircrafts, which will use this procedure, by other means. After aircraft enters into the clouds, the next one is not able to determine whether and how far ahead this procedure uses a different plane.

As appropriate, therefore, appears to be the use of waypoint for holding. This waypoint would be the same as the waypoint for start the descent. Depending on the height required for descend through clouds and average speeds it would be required to define a number of holding patterns to fly before starting descending.

Figure 4. CBP without Restricted Area
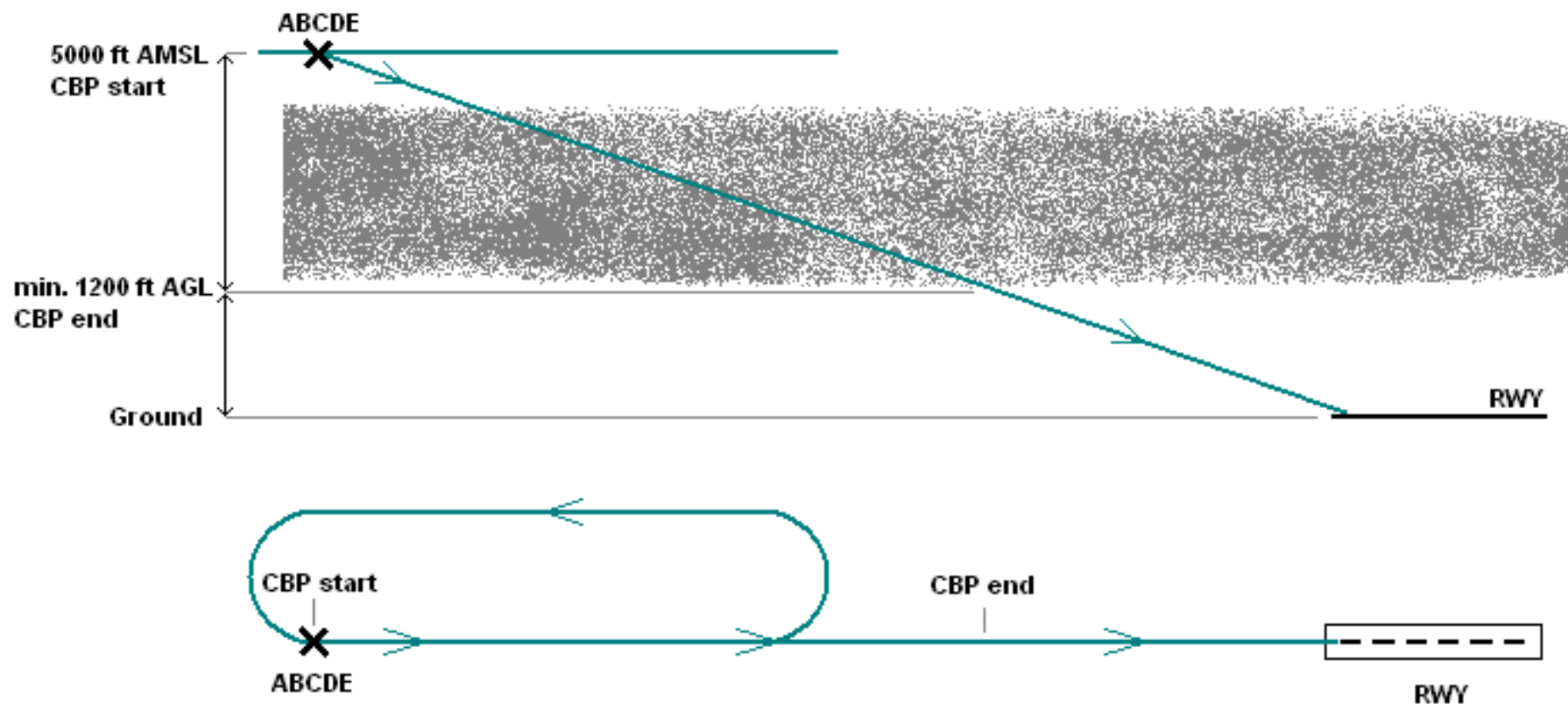
The following procedure would be the same as in the case of restricted area. The aircraft would flyover waypoint and began descending at a constant rate and speed and after finishing descent through clouds, the pilot would fly according to his will. Similarly, the pilot must have prior information about the height of cloud base, respectively procedure "missed descent" must be defined.

\section{CONCLUSION}

The use of Cloud Brake Procedures seems to be an appropriate step to improve air serviceability of Czech Republic. Whatever, CBP introduced as the final phase of IFR flight to VFR destination airport, or safety procedures in view of sudden deterioration of weather conditions, it will always have a positive impact on the Czech General Aviation.

To select specific aerodromes or places where CBP should be published, it must be created traffic statistics at individual aerodromes and add them together with meteorological information of given area.

\section{ACKNOWLEDGEMENTS}

This paper was supported by the Grant Agency of the Czech Technical University in Prague, grant No. SGS12/165/OHK2/2T/16.

\section{REFERENCES}

[1] AIP ČR [online]. Available at $<$ http://lis.rlp.cz/ais_data/www_main_control/frm_cz_aip.ht $\mathrm{m}>$

[2] AIP Iceland [online]. Available at <http://www.caa.is/FlugmalahandbokinAIP/>

[3] L standards - ICAO Annexes [online]. Available at <http://lis.rlp.cz/predpisy/predpisy/index.htm>

[4] EAD Basic [online]. EUROCONTROL. [cit. 2012-12-28]. Available at

<http://www.ead.eurocontrol.int/publicuser/public/pu/logou t.do;jsessionid=yW2sPgQp70QGcVnNhzvNs6DhtDvML43 nyyvbttQ2V60y2yn3GTGh!942399925> 